\title{
Effects of Torasemide on Left Ventricular Function and Neurohumoral Factors in Patients With Chronic Heart Failure
}

\author{
Masaki Yamato, MD; Tatsuya Sasaki, MD; Kaduo Honda, MD; Masayuki Fukuda, MD; \\ Osamu Akutagawa, MD; Masakuni Okamoto, MD; Takaharu Hayashi, MD
}

\begin{abstract}
The effect of torasemide and furosemide therapy was compared in 50 patients who had chronic heart failure and symptoms [NYHA class II-III] despite long-term therapy with both low-dose furosemide and angiotensinconverting enzyme inhibitors. In this randomized 6-month, open-label trial, baseline and follow-up echocardiograms and neurohumoral assays were obtained in 25 group $\mathrm{F}$ patients (continued same dose of oral furosemide at $20-40 \mathrm{mg} /$ day) and in 25 group $\mathrm{T}$ patients (received torasemide at $4-8 \mathrm{mg} /$ day in place of furosemide). At 6 months, parameters were unchanged in group $\mathrm{F}$ whereas the group $\mathrm{T}$ patients had a lower left ventricular enddiastolic diameter $(\mathrm{p}<0.005)$ and left ventricular mass index $(\mathrm{p}<0.005)$ with improved Doppler filling parameters, decreased plasma B-type natriuretic concentration $(\mathrm{p}<0.001)$ and increased plasma concentrations of active renin $(p<0.005)$ and aldosterone $(p<0.001)$. The magnitude of these changes appeared dose dependent and it is suggested these favorable effects of switching from furosemide to torasemide may be related to aldosterone receptor blockade. (Circ J 2003; 67: 384-390)
\end{abstract}

Key Words: Aldosterone; B-type natriuretic peptide; Chronic heart failure; Diastolic function; Torasemide

D iuretic therapy is a core element in the treatment of chronic heart failure (CHF) because diuretics relieve cardiac load by reducing water retention. Torasemide, a pyridine-sulfonylurea loop diuretic, is reportedly more effective than furosemide in $\mathrm{CHF}$, reducing symptoms, admissions and other adverse cardiovascular events, ${ }^{1,2}$ In a recent report of the prospective TORIC study involving 1,377 CHF patients in Spain, use of torasemide was associated with a lower mortality than furosemide? Both diuretics, torasemide and furosemide, exert similar renal effects, 4 which suggests that torasemide has beneficial effects other than diuresis in patients with CHF. However, it has not been determined whether torasemide, compared with furosemide, has a more beneficial effect on left ventricular (LV) function in patients with CHF.

The renin-angiotensin-aldosterone (RAA) system affects myocardial fibrosis and plays an important role in LV remodeling6 Recently, it was reported that torasemide may block the RAA system ${ }^{7-11}$ and therefore, it might attenuate myocardial remodeling and improve LV function in patients with CHF. However, it has not been elucidated whether torasemide, compared with furosemide, has more beneficial effects on the RAA system in patients with CHF.

The aim of this study is to evaluate the effects of the crossover from furosemide to torasemide on LV function using 2-dimensional (D) and Doppler echocardiographic parameters, and on neurohumoral factors, including the plasma B-type natriuretic peptide (BNP) and aldosterone concentrations in patients with CHF already receiving an

(Received October 2, 2002; revised manuscript received January 23, 2003; accepted February 4, 2003)

Division of Cardiology, Osaka Kosei-nenkin Hospital, Osaka, Japan Mailing address: Tatsuya Sasaki, MD, PhD, Division of Cardiology, Osaka Kosei-nenkin Hospital, 4-2-78 Fukushima, Fukushima-ku, Osaka 553-0003, Japan. E-mail: st8606@fw.okn.gr.jp angiotensin-converting enzyme inhibitor (ACEI).

\section{Methods}

\section{Subjects}

This 6-month, open-label, parallel, crossover study involved 50 outpatients with chronic, stable, moderate $\mathrm{CHF}$ [New York Heart Association (NYHA) class II or III], LV end-diastolic diameter (LVDd) at least $60 \mathrm{~mm}$ and a LV ejection fraction (LVEF) of $45 \%$ or less despite more than 1 year of treatment with ACEI and 20 or $40 \mathrm{mg}$ oral furosemide daily. The cause of heart failure was old myocardial infarction without current angina pectoris in 25, hypertensive heart disease with LV systolic dysfunction in 13, aortic valve insufficiency in 7, and idiopathic dilated cardiomyopathy in 5 patients. Patients with hyponatremia (serum $\mathrm{Na}$ $<135 \mathrm{nmol} / \mathrm{L}$ ), hypokalemia (serum potassium $<3.5 \mathrm{nmol} / \mathrm{L}$ ), renal insufficiency (serum creatinine $>2.5 \mathrm{mg} / \mathrm{dl}$ ), or more than mild mitral regurgitation by color Doppler echocardiography were excluded. Patients who were given spironolactone were also excluded. Clinical characteristics and baseline medications are shown in Table 1 . The background cardiovascular medications were withheld for at least 1 year for $\beta$ blockers and for at least 6 months for others, and they were maintained through the study period. Oral potassium chloride was discontinued when oral furosemide was crossed over to oral torasemide. All patients provided informed consent prior to participation, and the protocol was approved by the institutional Ethics Committee.

\section{Study Protocol}

Patients were enrolled in a 6-month, open-label, parallel study and were randomized either to continue on their current stable $20-40 \mathrm{mg} /$ day dose of oral furosemide (group F: $\mathrm{n}=25$ ) or changed to oral torasemide at a dose with compa- 
rable diuretic efficacy at 4-8 mg/day (group T: $n=25$ ), 3,4 Therefore, 11 group $\mathrm{T}$ patients who had taken furosemide at $20 \mathrm{mg}$ /day received torasemide at $4 \mathrm{mg} /$ day (group T-4) and 14 who had taken furosemide $40 \mathrm{mg} /$ day received torasemide at $8 \mathrm{mg} /$ day (group T-8), and 10 group $\mathrm{F}$ patients continued on furosemide at $20 \mathrm{mg} /$ day (group F-20) and 15 continued on furosemide at $40 \mathrm{mg} /$ day (group F-40). Outcome parameters examined before and after 6 months included (1) plasma BNP concentration, plasma active renin concentration (PARC), aldosterone and norepinephrine as well as serum potassium, (2) left atrial end-systolic diameter, LVDd, LVEF, LV mass index (LVMI) and inferior vena cava diameter, as well as Doppler filling parameters (peak $\mathrm{E}$ and $\mathrm{A}$ velocities, E/A ratio, $\mathrm{E}$ wave deceleration time or DcT and isovolemic relaxation time or IRT), (3) systolic and diastolic blood pressure (SBP, DBP), and pulse together with body weight, and (4) NYHA class.

\section{Measurements}

Blood samples were drawn by venipuncture after at least $30 \mathrm{~min}$ of rest with the patient in the supine position. Samples were placed immediately in a prechilled tube containing sodium EDTA and centrifuged at 3,000 rpm for 10 min. Plasma concentrations of BNP (Shionoria BNP Kit; Shionogi, Osaka, Japan), PARC (128I Renin IRMA Daiichi; TFB Inc, Tokyo, Japan) and aldosterone (SPAC-S Aldosterone Kit; Dainabot Inc, Tokyo, Japan) were measured by radioimmunoassay using the commercial kits. The plasma norepinephrine concentration was measured by high-performance liquid chromatography. LVEF, LVDd, LVMI and inferior vena cava diameter were determined by 2-D echocardiography, ${ }^{12,13}$ and peak $\mathrm{E}$ and $\mathrm{A}$ velocities, E/A ratio, DcT and IRT were obtained by Doppler echocardiography 14 The 2-D and Doppler echocardiographic values were calculated by at least 2 investigators as the mean of at least 3 consecutive beats for patients in sinus rhythm $(n=29)$ and, except for peak $E$ and A velocities and E/A ratio, at least 7 consecutive beats for patients in atrial fibrillation or flutter $(n=21)$. The echocardiographic operators were unaware of the patient allocation.

\section{Statistical Analysis}

All results are expressed as mean \pm standard deviation (SD). Comparison of baseline and post-study data were
Table 1 Baseline Demographics, Clinical Characteristics and Medication

\begin{tabular}{lcc}
\hline \hline & $\begin{array}{c}\text { Group F } \\
(n=25)\end{array}$ & $\begin{array}{c}\text { Group T } \\
(n=25)\end{array}$ \\
\hline $\begin{array}{l}\text { Age (years) } \\
\text { M/F }\end{array}$ & $64.9 \pm 6.2$ & $64.7 \pm 6.1$ \\
Etiology & $15 / 10$ & $14 / 11$ \\
OMI & $12(48 \%)$ & $13(52 \%)$ \\
HHD & $6(24 \%)$ & $7(28 \%)$ \\
AI & $4(16 \%)$ & $3(12 \%)$ \\
DCM & $3(12 \%)$ & $2(8 \%)$ \\
Sinus rhythm/Af or AF & $13 / 12$ & $14 / 11$ \\
NYHA class & & \\
II & $9(36 \%)$ & $8(32 \%)$ \\
III & $16(64 \%)$ & $17(68 \%)$ \\
Medications & & \\
ACE I & $25(100 \%)$ & $25(100 \%)$ \\
Diuretics & & \\
$\quad$ Furosemide 20mg daily & $10(40 \%)$ & $11(44 \%)$ \\
$\quad$ Furosemide 40 mg daily & $15(60 \%)$ & $14(56 \%)$ \\
Digitalis & $15(60 \%)$ & $16(64 \%)$ \\
Beta blockade & $15(60 \%)$ & $17(68 \%)$ \\
Nitrate & $4(16 \%)$ & $5(20 \%)$ \\
Oral potassium chloride & $18(72 \%)$ & $17(68 \%)$ \\
\hline
\end{tabular}

$A C E I$, angiotensin-converting enzyme inhibitor; Af, atrial fibrillation; $A F$, atrial flutter; AI, aortic valve insufficiency; DCM, idiopathic dilated cardiomyopathy; Group F, furosemide; Group T, torasemide; HHD, hypertensive heart disease; NYHA, New York Heart Association; OMI, old myocardial infarction.

performed using the paired t test or Wilcoxon single-rank test as appropriate. Intergroup differences were compared using Student's t test. Dose-dependent effects of torasemide on LV functional parameters and neurohumoral factors were assessed by repeated measure analysis of variance (ANOVA) methods and Scheffe's F test. Linear regression analysis was used to test the correlation between continuous variables. A probability value less than 0.05 was regarded as statistically significant.

\section{Results}

Background characteristics and parameters were similar between groups $\mathrm{F}$ and $\mathrm{T}$ (Table 1 ) and between the subgroups F-20 and T-4, and F-40 and T-8 (Table 2). There

Table 2 Baseline Demographics, Clinical Characteristics, and Medications in the Subgroups

\begin{tabular}{|c|c|c|c|c|}
\hline & Group F-20 & Group F-40 & Group T-4 & Group $T-8$ \\
\hline Age (years) & $64.7 \pm 6.2$ & $64.9 \pm 6.2$ & $64.4 \pm 6.1$ & $64.9 \pm 6.4$ \\
\hline$M / F$ & $5 / 5$ & $9 / 6$ & $6 / 5$ & $8 / 6$ \\
\hline \multicolumn{5}{|l|}{ Etiology } \\
\hline$O M I$ & $5(50 \%)$ & $7(47 \%)$ & $5(45 \%)$ & $8(58 \%)$ \\
\hline$H H D$ & $4(40 \%)$ & $3(20 \%)$ & $5(45 \%)$ & $2(14 \%)$ \\
\hline$A I$ & $1(10 \%)$ & $3(20 \%)$ & $0(0 \%)$ & $3(21 \%)$ \\
\hline$D C M$ & $0(0 \%)$ & $2(13 \%)$ & $1(10 \%)$ & $1(7 \%)$ \\
\hline Sinus rhythm/Af or $A F$ & $5 / 5$ & $8 / 7$ & $6 / 5$ & $8 / 6$ \\
\hline \multicolumn{5}{|l|}{ NYHA class } \\
\hline II & $5(50 \%)$ & $4(27 \%)$ & $5(45 \%)$ & $3(21 \%)$ \\
\hline III & $5(50 \%)$ & $11(73 \%)$ & $6(55 \%)$ & $11(79 \%)$ \\
\hline \multicolumn{5}{|c|}{ Medications other than diuretics } \\
\hline$A C E I$ & $10(100 \%)$ & $15(100 \%)$ & $11(100 \%)$ & $14(100 \%)$ \\
\hline Digitalis & $5(50 \%)$ & $11(73 \%)$ & $6(55 \%)$ & $11(79 \%)$ \\
\hline Beta blockade & $4(40 \%)$ & $9(60 \%)$ & $7(64 \%)$ & $8(57 \%)$ \\
\hline Nitrate & $1(10 \%)$ & $3(20 \%)$ & $2(18 \%)$ & $3(21 \%)$ \\
\hline Oral potassium chloride & $6(60 \%)$ & $12(80 \%)$ & $7(64 \%)$ & $10(71 \%)$ \\
\hline
\end{tabular}

Abbreviations as in Table 1 and in text. 
Table 3 Hemodynamic and Doppler-Echocardiographic Parameters and Neurohumoral Factors

\begin{tabular}{|c|c|c|c|c|}
\hline & \multicolumn{2}{|c|}{ Group F $(n=25)$} & \multicolumn{2}{|c|}{ Group $T(n=25)$} \\
\hline & Baseline & 6 months & Baseline & 6 months \\
\hline Heart rate (beats/min) & $71.8 \pm 11.5$ & $72.3 \pm 11.7$ & $70.2 \pm 10.7$ & $69.8 \pm 11.0$ \\
\hline $\mathrm{SBP}(\mathrm{mmHg})$ & $120.0 \pm 10.1$ & $119.8 \pm 10.8$ & $123.6 \pm 10.7$ & $123.0 \pm 10.0$ \\
\hline$D B P(m m H g)$ & $73.9 \pm 9.1$ & $73.8 \pm 8.6$ & $74.2 \pm 8.2$ & $73.3 \pm 8.0$ \\
\hline Body weight ( $k g$ ) & $61.4 \pm 10.9$ & $61.2 \pm 11.2$ & $60.4 \pm 11.8$ & $60.5 \pm 11.8$ \\
\hline NYHA class & $2.6 \pm 0.5$ & $2.6 \pm 0.5$ & $2.7 \pm 0.5$ & $2.6 \pm 0.5$ \\
\hline$L A D(\mathrm{~mm})$ & $43.9 \pm 3.2$ & $44.2 \pm 2.8$ & $44.3 \pm 3.6$ & $43.4 \pm 2.9$ \\
\hline $\operatorname{LVDd}(\mathrm{mm})$ & $65.3 \pm 3.2$ & $65.5 \pm 3.3$ & $64.6 \pm 3.0$ & $63.2 \pm 3.0 * \frac{1+}{t}$ \\
\hline $\operatorname{LVMI}\left(\mathrm{g} / \mathrm{m}^{2}\right)$ & $203.0 \pm 13.6$ & $206.7 \pm 17.5$ & $198.5 \pm 18.4$ & $191.1 \pm 18.6^{* *+}$ \\
\hline $\operatorname{LVEF}(\%)$ & $40.2 \pm 3.2$ & $39.7 \pm 3.5$ & $39.2 \pm 3.5$ & $39.6 \pm 4.0$ \\
\hline $\operatorname{IVCD}(\mathrm{mm})$ & $15.0 \pm 4.2$ & $14.9 \pm 4.0$ & $14.4 \pm 4.3$ & $14.2 \pm 4.1$ \\
\hline Peak E velocity $(\mathrm{m} / \mathrm{s})$ & $0.38 \pm 0.07$ & $0.37 \pm 0.07$ & $0.36 \pm 0.08$ & $0.39 \pm 0.09^{\dagger}$ \\
\hline Peak A velocity $(\mathrm{m} / \mathrm{s})$ & $0.93 \pm 0.14$ & $0.93 \pm 0.13$ & $0.89 \pm 0.15$ & $0.90 \pm 0.12$ \\
\hline E/A ratio & $0.41 \pm 0.05$ & $0.40 \pm 0.05$ & $0.40 \pm 0.06$ & $0.43 \pm 0.06^{1+}$ \\
\hline$D c T(m s)$ & $246.5 \pm 39.4$ & $244.7 \pm 38.6$ & $253.8 \pm 35.4$ & $235.8 \pm 36.9$ \\
\hline $\operatorname{IRT}(\mathrm{ms})$ & $101.1 \pm 10.6$ & $102.5 \pm 10.5$ & $100.8 \pm 10.5$ & $96.2 \pm 9.9 *$ \\
\hline$B N P(\mathrm{pg} / \mathrm{ml})$ & $324.5 \pm 77.4$ & $331.2 \pm 76.6$ & $326.3 \pm 73.1$ & $280.0 \pm 83.5^{\text {t⿱⿱亠䒑十}}$ \\
\hline $\operatorname{PARC}(\mathrm{pg} / \mathrm{ml})$ & $144.4 \pm 53.6$ & $153.1 \pm 57.8$ & $141.7 \pm 51.6$ & $191.7 \pm 66.9$ *t+ \\
\hline$A L D(p g / m l)$ & $103.2 \pm 25.1$ & $105.0 \pm 30.2$ & $97.8 \pm 23.8$ & $124.3 \pm 19.9^{H+}$ \\
\hline Norepinephrine $(\mathrm{pg} / \mathrm{ml})$ & $457.8 \pm 73.0$ & $463.0 \pm 76.2$ & $468.6 \pm 80.7$ & $467.3 \pm 94.2$ \\
\hline$K(\mathrm{mmol} / \mathrm{L})$ & $4.2 \pm 0.3$ & $4.1 \pm 0.3$ & $4.1 \pm 0.3$ & $4.1 \pm 0.2$ \\
\hline
\end{tabular}

${ }^{*} p<0.005,{ }^{\dagger} p<0.001$ vs baseline; ${ }^{\ddagger} p<0.05$ vs Group F. Values are expressed as the mean $\pm S D$. Peak $E$ and $A$ velocities, and E/A ratios were determined only in patients with sinus rhythm (Group F: $n=15$; Group T: $n=14$ ). ALD, aldosterone; BNP, B-type natriuretic peptide; DBP, diastolic blood pressure; DcT, the deceleration time of the $E$ wave; Group F, furosemide; Group T, torasemide; IRT, isovolemic relaxation time; IVCD, inferior vena cava diameter; K, potassium; LAD, left atrial end-systolic dimension; LVDd, left ventricular end-diastolic diameter; LVEF, left ventricular ejection fraction; LVMI, left ventricular mass index; NYHA, New York Heart Association; PARC, plasma active renin concentration; SBP, systolic blood pressure.
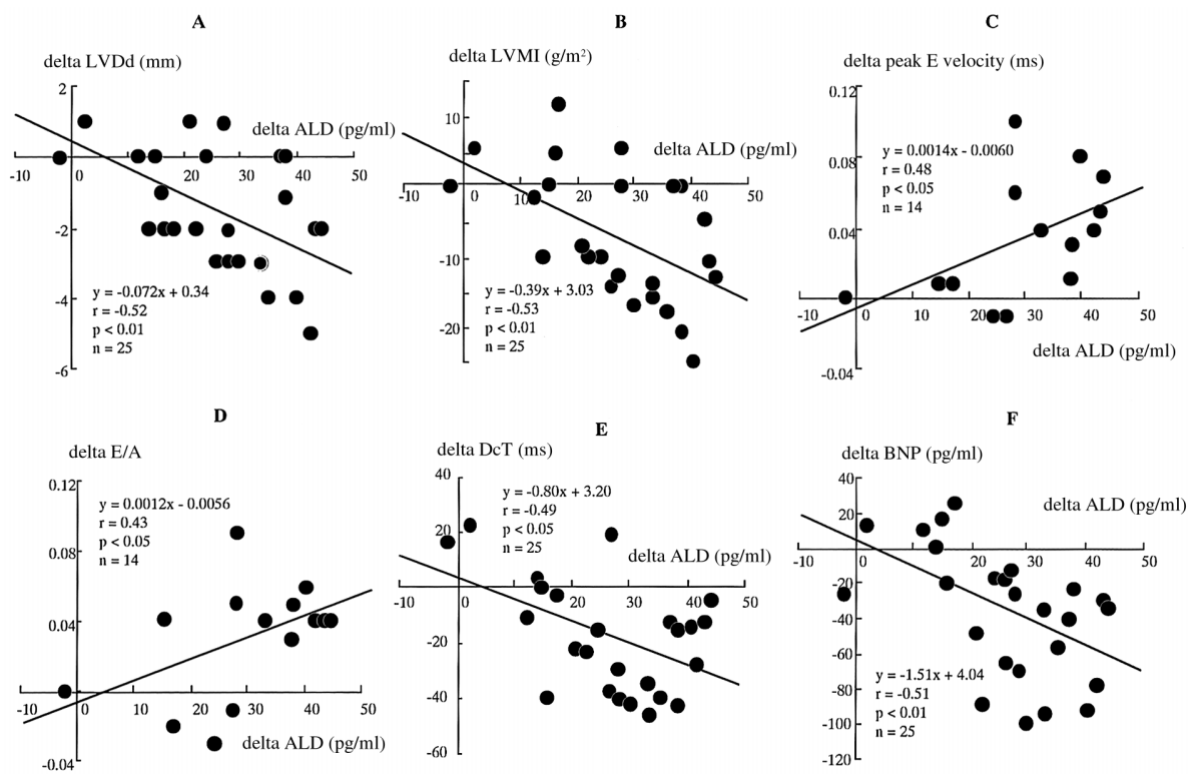

Fig 1. Correlation between the change in plasma aldosterone concentration and changes in Doppler echocardiographic parameters and plasma BNP concentration. Correlation between the change in plasma aldosterone concentration and changes of LVDd (A), LVMI (B), peak E velocity (C), E/A (D), DcT (E), and BNP (F). ALD, aldosterone; BNP, B-type natriuretic peptide; DcT, the deceleration time of the E wave; IRT, isovolemic relaxation time; LVMI, left ventricular mass index

were no deaths or hospitalizations because of heart failure during the study. At 6 months, NYHA class, SBP and DBP, heart rate, grade of mitral regurgitation and body weight were unchanged in both groups.

Comparison of 2-D and Doppler Echocardiographic Parameters and Neurohumoral Factors

At baseline, E/A ratios were less than 0.5, and DcT and
IRT were prolonged ( $>240 \mathrm{~ms}$ and $>100 \mathrm{~ms}$, respectively) in both groups, suggesting an 'abnormal relaxation' pattern (Table 3). No patients had a 'pseudonormal' or a 'restrictive filling' pattern in transmitral flow at baseline. At 6 months, in group $\mathrm{T}$, peak $\mathrm{E}$ velocity and $\mathrm{E} / \mathrm{A}$ ratio were increased $(\mathrm{p}<0.001)$, and DcT $(\mathrm{p}<0.001)$ and IRT $(\mathrm{p}<0.005)$ were shortened. Additionally LVDd $(\mathrm{p}<0.005)$ and LVMI $(\mathrm{p}<$ 0.005 ) were reduced, the plasma BNP concentration was 
Table 4 Doppler Echocardiographic Parameters and Neurohumoral Factors in Group F-20 and Group T-4

\begin{tabular}{|c|c|c|c|c|}
\hline & \multicolumn{2}{|c|}{ Group F-20 $(n=10)$} & \multicolumn{2}{|c|}{ Group $T-4(n=11)$} \\
\hline & Baseline & 6 months & Baseline & 6 months \\
\hline Heart rate (beats/min) & $71.8 \pm 11.5$ & $72.3 \pm 11.7$ & $70.2 \pm 10.7$ & $69.8 \pm 11.0$ \\
\hline$S B P(m m H g)$ & $120.0 \pm 10.1$ & $119.8 \pm 10.8$ & $123.6 \pm 10.7$ & $123.0 \pm 10.0$ \\
\hline$D B P(m m H g)$ & $75.2 \pm 6.7$ & $75.4 \pm 5.7$ & $74.9 \pm 5.7$ & $72.7 \pm 9.6$ \\
\hline Body weight $(\mathrm{kg})$ & $61.4 \pm 10.9$ & $61.2 \pm 11.2$ & $60.4 \pm 11.8$ & $60.5 \pm 11.8$ \\
\hline NYHA class & $2.6 \pm 0.5$ & $2.6 \pm 0.5$ & $2.7 \pm 0.5$ & $2.6 \pm 0.5$ \\
\hline$L A D(\mathrm{~mm})$ & $42.2 \pm 3.2$ & $43.1 \pm 2.6$ & $44.3 \pm 3.6$ & $43.4 \pm 3.0$ \\
\hline $\operatorname{LVDd}(\mathrm{mm})$ & $64.0 \pm 3.7$ & $65.7 \pm 3.4$ & $63.6 \pm 3.3$ & $63.5 \pm 3.3$ \\
\hline $\operatorname{LVMI}\left(\mathrm{g} / \mathrm{m}^{2}\right)$ & $200.3 \pm 12.3$ & $210.7 \pm 13.7$ & $204.4 \pm 16.7$ & $199.4 \pm 16.0$ \\
\hline $\operatorname{LVEF}(\%)$ & $40.2 \pm 3.3$ & $39.8 \pm 3.6$ & $40.2 \pm 3.5$ & $38.9 \pm 4.6$ \\
\hline$I V C D(\mathrm{~mm})$ & $14.5 \pm 4.5$ & $15.0 \pm 4.4$ & $13.8 \pm 4.5$ & $14.4 \pm 3.8$ \\
\hline Peak E velocity $(\mathrm{m} / \mathrm{s})$ & $0.38 \pm 0.04$ & $0.38 \pm 0.05$ & $0.34 \pm 0.06$ & $0.37 \pm 0.09$ \\
\hline Peak A velocity $(\mathrm{m} / \mathrm{s})$ & $0.94 \pm 0.10$ & $0.93 \pm 0.09$ & $0.83 \pm 0.14$ & $0.84 \pm 0.13$ \\
\hline E/A ratio & $0.41 \pm 0.07$ & $0.41 \pm 0.08$ & $0.42 \pm 0.05$ & $0.44 \pm 0.06$ \\
\hline$D c T(m s)$ & $247.5 \pm 32.6$ & $245.8 \pm 31.6$ & $253.2 \pm 30.6$ & $237.1 \pm 38.9^{\#}$ \\
\hline $\operatorname{IRT}(\mathrm{ms})$ & $95.3 \pm 8.8$ & $97.1 \pm 9.8$ & $98.0 \pm 11.5$ & $97.1 \pm 11.9$ \\
\hline$B N P(p g / m l)$ & $303.3 \pm 48.8$ & $307.4 \pm 52.3$ & $330.3 \pm 71.4$ & $310.8 \pm 88.1$ \\
\hline $\operatorname{PARC}(\mathrm{pg} / \mathrm{ml})$ & $126.2 \pm 55.7$ & $124.6 \pm 30.2$ & $134.6 \pm 51.4$ & $192.4 \pm 67.3^{\# \pi}$ \\
\hline$A L D(p g / m l)$ & $100.4 \pm 28.4$ & $100.2 \pm 33.5$ & $97.9 \pm 25.9$ & $118.7 \pm 18.3 *$ \\
\hline Norepinephrine $(\mathrm{pg} / \mathrm{ml})$ & $440.4 \pm 65.2$ & $444.3 \pm 73.0$ & $464.4 \pm 84.7$ & $460.2 \pm 97.2$ \\
\hline
\end{tabular}

${ }^{\#} p<0.05,{ }^{*} p<0.005$ vs baseline; ${ }^{4} p<0.01$ vs Group F-20. Values are expressed as the mean \pm SD. Abbreviations as in Table 3.

Table 5 Doppler Echocardiographic Parameters and Neurohumoral Factors in Group F-40 and Group T-8

\begin{tabular}{|c|c|c|c|c|}
\hline & \multicolumn{2}{|c|}{ Group F-40 $(n=15)$} & \multicolumn{2}{|c|}{ Group T-8 $(n=14)$} \\
\hline & Baseline & 6 months & Baseline & 6 months \\
\hline Heart rate (beats/min) & $71.8 \pm 11.5$ & $72.3 \pm 11.7$ & $70.2 \pm 10.7$ & $69.8 \pm 11.0$ \\
\hline$S B P(m m H g)$ & $120.0 \pm 10.1$ & $119.8 \pm 10.8$ & $123.6 \pm 10.7$ & $123.0 \pm 10.0$ \\
\hline$D B P(m m H g)$ & $73.1 \pm 10.5$ & $72.7 \pm 10.1$ & $73.7 \pm 10.0$ & $72.7 \pm 9.6$ \\
\hline Body weight (kg) & $61.4 \pm 10.9$ & $61.2 \pm 11.2$ & $60.4 \pm 11.8$ & $60.5 \pm 11.8$ \\
\hline NYHA class & $2.6 \pm 0.5$ & $2.6 \pm 0.5$ & $2.7 \pm 0.5$ & $2.6 \pm 0.5$ \\
\hline$L A D(m m)$ & $45.0 \pm 2.8$ & $44.9 \pm 2.8$ & $44.3 \pm 3.7$ & $43.4 \pm 3.0$ \\
\hline $\operatorname{LVDd}(\mathrm{mm})$ & $66.2 \pm 2.5$ & $65.3 \pm 3.3$ & $65.6 \pm 2.9$ & $63.0 \pm 2.8^{b}$ \\
\hline $\operatorname{LVMI}\left(\mathrm{g} / \mathrm{m}^{2}\right)$ & $204.7 \pm 14.6$ & $204.1 \pm 19.6$ & $193.9 \pm 19.0$ & $184.6 \pm 18.4 *$ \\
\hline $\operatorname{LVEF}(\%)$ & $40.2 \pm 3.2$ & $40.0 \pm 3.6$ & $38.2 \pm 3.3$ & $40.2 \pm 3.5^{*}$ \\
\hline $\operatorname{IVCD}(\mathrm{mm})$ & $15.3 \pm 4.2$ & $14.8 \pm 3.9$ & $14.9 \pm 4.2$ & $14.0 \pm 4.5$ \\
\hline Peak E velocity $(\mathrm{m} / \mathrm{s})$ & $0.38 \pm 0.08$ & $0.37 \pm 0.08$ & $0.37 \pm 0.09$ & $0.40 \pm 0.09^{b}$ \\
\hline Peak A velocity $(\mathrm{m} / \mathrm{s})$ & $0.92 \pm 0.16$ & $0.92 \pm 0.15$ & $0.94 \pm 0.14$ & $0.94 \pm 0.11$ \\
\hline E/A ratio & $0.42 \pm 0.06$ & $0.40 \pm 0.05$ & $0.39 \pm 0.06$ & $0.43 \pm 0.07 *$ \\
\hline $\operatorname{DcT}(m s)$ & $245.9 \pm 44.5$ & $243.9 \pm 43.7$ & $254.4 \pm 40.0$ & $234.8 \pm 36.7 *$ \\
\hline $\operatorname{IRT}(\mathrm{ms})$ & $104.8 \pm 10.1$ & $106.1 \pm 9.7$ & $103.0 \pm 9.4$ & $95.5 \pm 8.4 * \pi$ \\
\hline$B N P(p g / m l)$ & $338.6 \pm 90.6$ & $347.3 \pm 87.3$ & $305.3 \pm 75.2$ & $256.4 \pm 74.2^{\dagger q l}$ \\
\hline $\operatorname{PARC}(\mathrm{pg} / \mathrm{ml})$ & $156.6 \pm 50.3$ & $172.1 \pm 64.4$ & $147.2 \pm 53.0$ & $191.1 \pm 69.1^{\#}$ \\
\hline$A L D(p g / m l)$ & $104.9 \pm 23.5$ & $108.3 \pm 28.5$ & $97.6 \pm 22.2$ & $128.6 \pm 20.7^{\dagger+1}$ \\
\hline Norepinephrine $(\mathrm{pg} / \mathrm{ml})$ & $469.5 \pm 77.8$ & $475.5 \pm 78.1$ & $471.9 \pm 80.5$ & $472.9 \pm 95.1$ \\
\hline
\end{tabular}

${ }^{\#} p<0.05,{ }^{b} p<0.01,{ }^{*} p<0.005,{ }^{\dagger} p<0.001$ vs baseline; ${ }^{*} p<0.05$, ${ }^{q} p<0.01$ vs Group $F$. Values are expressed as the mean $\pm S D$. Abbreviations as in Table 3 .

lowered $(\mathrm{p}<0.001)$, PARC was increased $(\mathrm{p}<0.001)$ and plasma aldosterone concentration was increased $(\mathrm{p}<0.001)$. Other variables, including left atrial end-systolic dimension, LVEF, and inferior vena cava diameter did not change (Table 3 ). None of these parameters changed in group F. Consequently, LVDd was smaller ( $<<0.05$ ), LVMI was smaller $(p<0.05)$, E/A was greater $(p<0.05)$, PARC was higher $(\mathrm{p}<0.05)$, plasma aldosterone concentration was higher $(\mathrm{p}<0.05)$, and plasma BNP concentration was lower $(\mathrm{p}<0.05)$ in group $\mathrm{T}$ than in group $\mathrm{F}$ at 6 months.

Relationship Between Changes in Plasma Aldosterone Concentration and Changes in Doppler Echocardiographic Parameters and Changes in Plasma BNP Concentration

In group $\mathrm{T}$, the increase in plasma aldosterone concentration correlated with the decreases in LVDd and
LVMI $(\mathrm{r}=-0.52, \mathrm{p}<0.01$ and $\mathrm{r}=-0.53, \mathrm{p}<0.01$, respectively; Fig $1 \mathrm{~A}, \mathrm{~B})$ and the increases in peak $\mathrm{E}$ velocity and E/A ratio $(\mathrm{r}=0.48, \mathrm{p}<0.05$ and $\mathrm{r}=0.43, \mathrm{p}<0.05$, respectively; Fig 1C,D), with the decreases in DcT $(r=-0.49, p<0.05$; Fig 1E) and plasma BNP concentration $(r=-0.51, p<0.01$; Fig 1F), but not with the decrease in IRT (Fig 1G).

Dose-Dependent Effects of Torasemide on 2-D and Doppler Echocardiographic Parameters and Neurohumoral Factors

Among the LV functional parameters and neurohumoral factors, DcT was shortened, and PARC and the plasma aldosterone concentration were increased in group $\mathrm{T}-4$, but none of these parameters changed in group F-20. Consequently, PARC was higher in group T-4 than in group F-20 at 6 months (Table4). Similarly, both LVDd and LVMI were reduced, peak $\mathrm{E}$ velocity and the E/A ratio were 


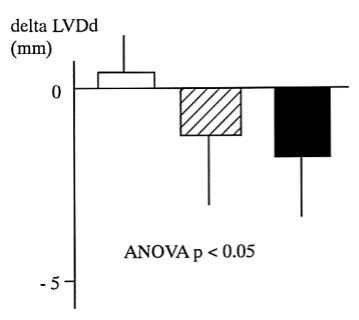

$\mathbf{D}$

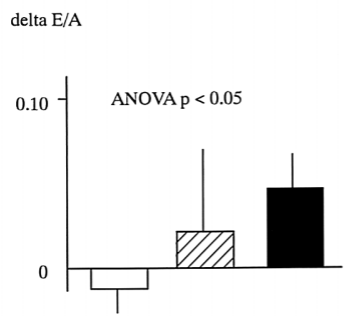

B

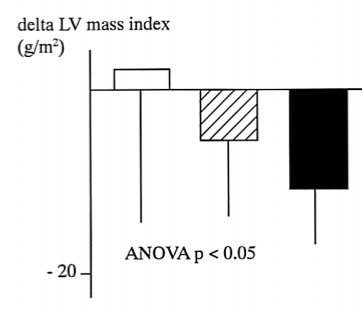

E

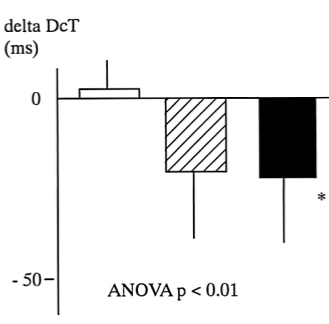

C delta peak E velocity (ms)

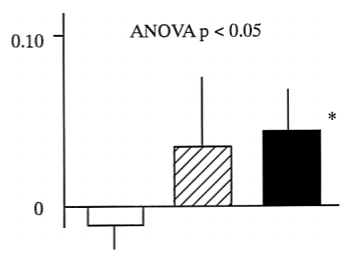

$\mathbf{F}$

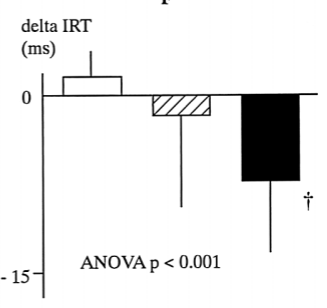

Fig 2. Dose-dependent effects of torasemide on Doppler echocardiographic parameters. Changes in LVDd (A), LVMI (B), peak E velocity (C), E/A (D), DcT (E), and IRT (F) in Group F (open bars), Group T-4 (hatched bars) and Group T-8 (solid bars). ${ }^{*} \mathrm{p}<0.05,{ }^{\dagger} \mathrm{p}<0.001$ vs group $\mathrm{F}-40$.

A

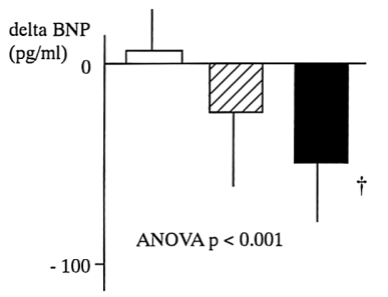

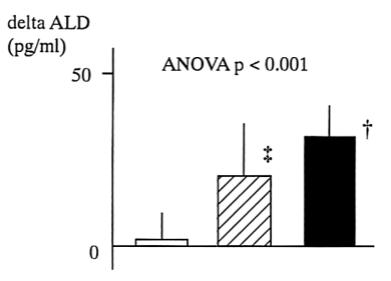

Fig 3. Dose-dependent effects of torasemide on plasma aldosterone and BNP concentrations. Changes in plasma aldosterone (A) and BNP (B) concentrations in Group F (open bars), Group T-4 (hatched bars) and Group T-8 (solid bars). ${ }^{\dagger} \mathrm{p}<0.001$ vs group F-40, ${ }^{\ddagger} \mathrm{p}<0.001$ vs group F-20.

increased, DcT and IRT were shortened, plasma BNP concentration was lowered, and PARC and plasma aldosterone concentration were increased in group $\mathrm{T}-8$, but were unchanged in group F-20. Consequently, the LVMI was smaller, IRT shorter, plasma aldosterone concentration higher, and plasma BNP concentration lower in group $\mathrm{T}$ than in group $\mathrm{F}$ at 6 months (Table 5).

Among these parameters, there was a dose-dependent effect of torasemide on LVDd ( $\mathrm{p}<0.05$; Fig 2A), LVMI ( $\mathrm{p}<$ 0.05 ; Fig $2 \mathrm{~B})$, peak E velocity $(\mathrm{p}<0.05$; Fig $2 \mathrm{C})$, E/A ratio $(\mathrm{p}<0.05$; Fig 2D), DcT $(\mathrm{p}<0.001$; Fig 2E), IRT $(\mathrm{p}<0.001$; Fig $2 \mathrm{~F})$, and the plasma concentrations of BNP $(\mathrm{p}<0.001$; Fig $3 \mathrm{~A})$ and aldosterone $(\mathrm{p}<0.001$; Fig $3 \mathrm{~B})$, with the greatest benefits from torasemide occurring in those patients treated with a higher dose.

\section{Discussion}

The present study demonstrates for the first time that treatment with oral torasemide improves LV diastolic function, LVDd and LVMI, as well as decreasing plasma BNP concentration in patients with $\mathrm{CHF}$, to a greater extent than oral furosemide, and that the effects of torasemide are dose dependent. Although the improvements in these parameters were not so evident in the group treated with a lower dose of torasemide, we still suggest that torasemide is more beneficial in managing CHF as compared with furosemide.

LV diastolic dysfunction is common in patients with LV systolic heart failure and relates to cardiac symptoms and prognosis $1^{15-17} \mathrm{LV}$ diastolic dysfunction is diagnosed as 'abnormal relaxation', 'restrictive filling' or 'pseudonormalization' based on the combination of Doppler transmitral flow velocities and IRT ${ }^{14}$ In the present study, the baseline E/A ratio was low, and DcT and IRT were prolonged, suggesting an 'abnormal relaxation' pattern. After the crossover in group T, E/A ratio, DcT and IRT tended toward a less 'abnormal relaxation' pattern, although these parameters did not completely normalize and the improvements in these parameters were not so evident in the group treated with a lower dose of torasemide, suggesting an improvement in LV diastolic function. The Doppler transmitral flow patterns depend on heart rate, pre- and afterload conditions, and the grade of mitral regurgitation! ${ }^{18,19}$ After the crossover in group $\mathrm{T}$, the preload appeared to be constant because the inferior vena cava diameter, body weight, and left atrial end-systolic dimension did not change; the afterload also was constant because SBP did not change. Furthermore, the heart rate and grade of mitral regurgitation remained the same after the crossover. Consequently, the changes in the Doppler transmitral flow parameters were unlikely to be attributable to any of these causes, and the improvement in the Doppler transmitral flow pattern in group $\mathrm{T}$ represents an improvement in LV diastolic function itself. This argument is supported by the fact that the plasma BNP concentration decreased after the crossover in group $\mathrm{T}$, although it did not completely normalize and the reduction in these parameters was not so evident in the group treated with a lower dose of torasemide, because plasma BNP concentration correlates with LV function, and with LV diastolic function in particular. The decrease in plasma BNP concentration observed in the present study was likely caused by a reduction in LV remodeling, and/or a decrease in LV filling pressure ?-22 $^{20}$

Aldosterone plays important role in regulating LV re- 
modeling. Myocardial fibrosis and/or LV mass increase are enhanced by the RAA system, which leads to myocardial remodeling and results in LV dysfunction in patients with CHF6,23,24 Although ACEI can reduce plasma aldosterone concentrations, the reduction is transient and the production of aldosterone is incompletely inhibited 25,26 This aldosterone escape phenomenon is supported by the Randomized Aldactone Evaluation Study (RALES), which showed that aldosterone antagonism with spironolactone reduces mortality in patients with severe CHF already receiving $\mathrm{ACEI} ; 29$ spironolactone can inhibit myocardial remodeling and improve $\mathrm{LV}$ function and exercise tolerance in $\mathrm{CHF}^{27,28,30,31}$ Torasemide also blocks the aldosterone receptor in vitro, and has been shown in rats to inhibit aldosterone-receptor binding dose-dependently in tubular cells 7.8 Rats receiving a 7-day course of torasemide had a higher plasma aldosterone concentration, 32 and similar findings have been reported for spironolactone in humans. ${ }^{27}$ Furosemide lacks these properties 32 Furthermore, even though torasemide is a potent loop diuretic, it causes less hypokalemia than furosemide, which is consistent with the contention that torasemide blocks aldosterone receptors. In the present study, although plasma aldosterone concentration was within normal range during the study, as in a previous report ${ }^{27}$ and the increase in plasma aldosterone concentration was not so evident in the group treated with a lower dose of torasemide, after the crossover in group $\mathrm{T}$ it was observed that PARC and plasma aldosterone concentration were increased after torasemide and the increase in plasma aldosterone concentration correlated inversely with the decrease in plasma BNP concentration and directly with the improvement in LVDd, LVMI and LV diastolic function, except for IRT. Furthermore, there was a dose-dependency of torasemide in the changes of LVDd, LVMI, LV diastolic function, PARC and plasma BNP and aldosterone concentrations in group $\mathrm{T}$. Thus it is suggested that oral torasemide attenuates myocardial remodeling and improves LV function by blocking aldosterone receptors in patients with CHF.

Serum potassium concentrations did not change during the present study, although oral potassium chloride was discontinued when oral furosemide was crossed over to oral torasemide: This result lends support to the aldosterone receptor blocking action of oral torasemide. Thus, the present results suggest the presence of the aldosterone escape phenomenon and LV reverse-remodeling after adding torasemide to the treatment of patients with $\mathrm{CHF}$ already receiving ACEI.

\section{Study Limitations}

Patients who were allocated to the torasemide group stopped their potassium supplementation. Because potassium affects aldosterone production ${ }^{33}$ the observed increase in the plasma aldosterone concentration may reflect mixed results of a potential decrease in endogenous aldosterone induced by a withdrawal of potassium supplementation and an actual increase via aldosterone receptor blockade by torasemide. To clarify this issue, further study is needed to assess the magnitude of aldosterone receptor blockade by torasemide alone.

It has been reported that torasemide inhibits aldosterone secretion by adrenal cells in vitro ${ }^{10}$ and that aldosterone is produced and secreted by the failing ventricle in humans 34 Consequently, oral torasemide may inhibit ventricular production and secretion of aldosterone locally, which could inhibit myocardial fibrosis. Further study is needed on this point. Furthermore, the present study did not measure the plasma concentration of procollagen type III aminoterminal peptide, which is a biochemical marker of LV fibrosis and remodeling in patients with $\mathrm{CHF}^{27,29,35}$ Therefore the present evidence that oral torasemide actually inhibits myocardial fibrosis is not unequivocal.

It has been reported that spironolactone may increase cardiac norepinephrine uptake and improve cardiac sympathetic activity in patients with $\mathrm{CHF}^{36}$ In the present study, the plasma norepinephrine concentration was unchanged after the crossover in group $\mathrm{T}$, but it cannot be denied that torasemide may influence cardiac sympathetic activity in patients with CHF. Further study is needed to assess the effects of torasemide on cardiac sympathetic activity in patients with CHF.

Patients in this study had an 'abnormal relaxation' pattern, as reflected in the transmitral flow parameters. We did not determine whether oral torasemide improves LV function in patients with a either a 'restrictive filling' or 'pseudonormalization' pattern. Also, the present study was an open-label, observational study involving a relatively small number of patients. Furthermore, previous reports have not clarified whether the effects of torasemide differ in CHF patients with different etiologies and of varying degrees of severity!-3,5 Therefore, a large-scale, randomized study involving a variety of types of diastolic dysfunction with different etiologies and of varying degrees of severity is needed to unequivocally establish the myocardial protective effects of oral torasemide and to assess which subgroup shows a favorable response to torasemide.

\section{Conclusions}

The results of the present study suggest that changing from oral furosemide to oral torasemide improves LV diastolic function and decreases the plasma BNP concentration in patients with CHF already receiving ACEI. The mechanism of action may be related to a dose-dependent blockade of aldosterone receptors by torasemide.

\section{Acknowledgments}

We would like to thank Kazuhiro Yamamoto MD, PhD of the Department of Internal Medicine and Therapeutics, Osaka University Graduate School of Medicine, and Tomoya Shimotori, Mikio Kawabata and Hirofumi Tomita of Toyama Chemical Co, Ltd for their valuable discussion.

\section{References}

1. Murray MD, Deer MM, Ferguson JA, Dexter PR, Bennett SJ, Perkins SM, et al. Open-label randomized trial of torasemide compared with furosemide therapy for patients with heart failure. Am $J$ Med 2001; 111: 513-520.

2. Spannheimer A, Goertz A, Dreckmann-Behrendt B. Comparison of therapies with torasemide or furosemide in patients with congestive heart failure from a pharmacoeconomic viewpoint. Int J Clin Pract 1998; 52: 467-471.

3. Cosín J, Diez J on behalf of the TORIC investigators. Torasemide in chronic heart failure: Results of the TORIC study. Eur J Heart Fail 2002; 4: 507-513.

4. Friedel HA, Buckley MM-T. Torasemide: A review of its pharmacological properties and therapeutic potential. Drugs 1991; 41: $81-$ 103.

5. Goebel KM. Six-week study of torasemide in patients with congestive heart failure. Clin Ther 1993; 15: 1051-1059.

6. Weber KT, Brilla C. Pathological hypertrophy and cardiac interstitium: Fibrosis and renin-angiotensin-aldosterone system. Circulation 1991; 83: 1849-1865. 
7. Uchida T, Yamanaga K, Nishikawa M, Ohtaki Y, Kido H, Watanabe M. Anti-aldosteronergic effect of torasemide. Eur J Pharmacol 1991; 205: $145-150$

8. Uchida T, Yamanaga K, Kido H, Ohtaki Y, Watanabe M. Diuretic and vasodilating actions of torasemide. Cardiology 1994; 84(Suppl 2): $14-17$.

9. Kido H, Ohtaki Y. Torasemide (LUPRAC ${ }^{\circledR}$ ): A review of its pharmacological and clinical profile. Folia Pharmacol Jpn (Nippon Yakurigaku Zasshi) 2001; 118: $97-105$.

10. Goodfriend TL, Ball DL, Oelkers W, Bähr V. Torasemide inhibits aldosterone secretion in vitro. Life Sci 1998; 63: 45-50.

11. Fortuno A, Muniz P, Ravassa S, Rodriguez JA, Fortuno MA, Zalba DJ. Torasemide inhibits angiotensin-II-induced vasoconstriction and intracellular calcium increase in the aorta of spontaneously hypertensive rats. Hypertension 1999; 34: 138-143.

12. Sahn DJ, DeMaria A, Kisslo J, Weyman A. The Committee on Mmode Standardization of the American Society of Echocardiography: Results of a survey of echocardiography measurements. Circulation 1978; 58: 1072-1083.

13. Moreno FLL, Hagan AD, Holmen JR, Pryor TA, Strickland RD, Castle $\mathrm{CH}$. Evaluation of size and dynamics of the inferior vena cava as an index of right-sided cardiac function. Am J Cardiol 1984; 53: $579-585$.

14. Nishimura RA, Tajik AJ. Quantitative hemodynamics by Doppler echocardiography: A noninvasive alternative to cardiac catheterization. Prog Cardiovasc Dis 1994; 36: 309-342.

15. Rihal CS, Nishimura RA, Hatle LK, Bailey KR, Tajik AJ. Systolic and diastolic dysfunction in patients with clinical diagnosis of dilated cardiomyopathy: Relation to symptoms and prognosis. Circulation 1994; 90: 2772-2779.

16. Xie GY, Berk MR, Smith MD, Gurley JC, DeMaria AN. Prognostic value of Doppler transmitral flow patterns in patients with congestive heart failure. J Am Coll Cardiol 1994; 24: 132 - 139.

17. Ohta T, Nakatani S, Izumi S, Nagata S, Beppu S, Miyatake K. Serial assessment of left nad right ventricular filling in patients with congestive heart failure. Jpn Circ J 2001; 65: 803-807.

18. Nishimura RA, Tajik AJ. Evaluation of diastolic filling of left ventricle in health and disease: Doppler echocardiography is the clinician's Rosetta stone. J Am Coll Cardiol 1997; 30: 8-18.

19. Yamamoto K, Redfield MM, Nishimura RA. Analysis of left ventricular diastolic function. Heart 1996; 75: 27-35.

20. Yamamoto K, Burnett JC Jr, Jougasaki M, Nishimura RA, Bailey $\mathrm{KR}$, Saito Y, et al. Superiority of brain natriuretic peptide as a hormonal marker of ventricular systolic and diastolic dysfunction and ventricular hypertrophy. Hypertension 1996; 28: 988-994.

21. Tsutamoto T, Wada A, Maeda K, Hisanaga T, Maeda Y, Fukai D, et al. Attenuation of compensation of endogenous cardiac natriuretic peptide system in chronic heart failure: Prognostic role of plasma brain natriuretic peptide concentration in patients with chronic symptomatic left ventricular dysfunction. Circulation 1997; 96: 509-516.

22. Maisel A. B-type natriuretic peptide levels: A potential novel 'White
Count' for congestive heart failure. J Card Fail 2001; 7: 183-193.

23. Young M, Fullerton M, Dilley R, Funder JW. Mineralocorticoids, hypertension, and cardiac fibrosis. J Clin Invest 1994; 92: $2578-$ 2583.

24. Patel AR, Konstan MA: Recent advances in the treatment of heart failure. Circ J 2002; 66: 117-121.

25. Struthers AD. Aldosterone escape during ACE inhibitor therapy in chronic heart failure. Eur Heart J 1995; 16(Suppl N): 103-106.

26. Jorde UP, Vittorio T, Katz SD, Colombo PC, Latif FL, Le Jemtel $\mathrm{TH}$. Elevated plasma aldosterone levels despite complete inhibition of the vascular angiotensin-converting enzyme in chronic heart failure. Circulation 2002; 106: 1055-1057.

27. Tsutamoto T, Wada A, Maeda K, Mabuchi N, Hayashi M, Tsutsui T, et al. Effect of spironolactone on plasma brain natriuretic peptide and left ventricular remodeling in patients with congestive heart failure. $J$ Am Coll Cardiol 2001; 37: 1228-1233.

28. Brilla CG, Matsubara LS, Weber KT. Antifibrotic effects of spironolactone in preventing myocardial fibrosis in systemic hypertension. Am J Cardiol 1993; 71: 12A-16A.

29. Pitt B, Zannad F, Remme WJ, Cody R, Castaigne A, Perez A, et al for the Randomized Aldactone Evaluation Study Investigators. The effect of spironolactone on mortality and morbidity in patients with severe heart failure. N Engl J Med 1999; 341: 709-717.

30. Yee K-M, Pringle SD, Struthers AD. Circadian validation in the effects of aldosterone blockade on heart rate variability and QT dispersion in congestive heart failure. J Am Coll Cardiol 2001; 37: $1800-1807$.

31. Cicoira M, Zanolla L, Rossi A, Golia G, Franceschini L, Brighetti G, et al. Long-term, dose-dependent effects of spironolactone on left ventricular function and exercise tolerance in patients with chronic heart failure. J Am Coll Cardiol 2002; 40: 304-310.

32. Shinyama H, Yamanaga K, Akira T, Uchida T, Watanabe M, Kagitani Y. Effects of single and repeated administration of torasemide on plasma renin activity and aldosterone concentration in rats. Clin Rep (Kiso to Rinsho) 1996; 30: 503-510.

33. Tremblay A, Waterman GH, Parker KL, Lehoux JG. Regulation of rat adrenal messenger RNA and protein levels for cytochrome P450 s and adrenodoxin by dietary sodium depletion or potassium intake. J Biol Chem 1991; 266: 2245-2251.

34. Mizuno Y, Yoshimura M, Yasie H, Sakamoto T, Ogawa H, Kugiyama $\mathrm{K}$, et al. Aldosterone production is activated in failing ventricle in humans. Circulation 2001; 103: $72-77$.

35. Host NB, Jensen LT, Bendixen PM, Jensen SE, Koldkjaer OG, Simonsen EE. The aminoterminal propeptide of type III procollagen provides new information on prognosis after acute myocardial infarction. Am J Cardiol 1995; 76: 869-873.

36. Barr CS, Lang CC, Hanson J, Arnott M, Kennedy N, Struther AD. Effects of adding spironolactone to an angiotensin-converting enzyme inhibitor in chronic congestive heart failure secondary to coronary artery disease. Am J Cardiol 1995; 76: 1259-1265. 